\title{
Association of social distance toward schizophrenia with help-seeking among mothers of adolescents in Japan
}

\author{
Hatsumi Yoshii ${ }^{1^{*}}$, Yuichiro Watanabe ${ }^{2,3}$, Hideaki Kitamura ${ }^{2}$, Atiqul Haq Mazumder ${ }^{4}$, \\ Kouhei Akazawa ${ }^{5}$ \\ ${ }^{1}$ School of Health Sciences, Faculty of Medicine, Tohoku University, Sendai, Japan; \\ *Corresponding Author: hatsumi@med.tohoku.ac.jp \\ ${ }^{2}$ Department of Psychiatry, Niigata University Graduate School of Medical and Dental Sciences, Niigata, Japan \\ ${ }^{3}$ Division of Medical Education, Comprehensive Medical Education Center, School of Medicine, Faculty of Medicine, Niigata Uni- \\ versity, Niigata, Japan \\ ${ }^{4}$ National Institute of Mental Health, Dhaka, Bangladesh \\ ${ }^{5}$ Department of Medical Informatics and Statistics, Niigata University Graduate School of Medicine, Niigata, Japan
}

Received 5 October 2012; revised 13 November 2012; accepted 21 November 2012

\section{ABSTRACT}

Negative maternal attitudes toward schizophrenia may be linked with delayed treatment of their children. We investigated the relation between negative attitudes toward schizophrenia and help-seeking among mothers of junior and senior high school students in Japan. The participants were 1309 Japanese mothers of junior and senior high school students. Social distance was evaluated by using the Social Distance Scale-Japanese version (SDS-J). In addition, mothers were asked about help-seeking for a child with sleeplessness, social withdrawal, and strange behavior. One-way analysis of variance and Student's t-test were used to evaluate associations between social distance toward schizophrenia and help-seeking. Most (76.4\%) participants were aged 40 - 49 years. Maternal demographic characteristics significantly associated with social distance were employment and participation in welfare activities for people with mental illness. In responding to a child with sleeplessness, social withdrawal, and strange behavior, the level of maternal social distance was not significantly associated with the likelyhood of seeking psychiatric help. However, mothers with greater social distance were less likely to seek help at a psychiatric clinic. Maternal social distance toward schizophrenia was not significantly associated with seeking psychiatric help; however, it did affect the type of facility selected among those would seek such help.
Keywords: Social Distance; Schizophrenia; Help-Seeking; Mothers; Adolescence

\section{INTRODUCTION}

Delayed treatment of schizophrenia is associated with worse outcomes [1], e.g. increases in medication required, risk of suicide, and duration of hospital stays $[2,3]$. Studies have revealed factors linked with delayed detection of schizophrenia [4-6]. One such factor is stigma toward schizophrenia [7]. Many people reject schizophrenia and do not accept individuals with the disorder in their communities [8,9]. Therefore, people with schizophrenia and their families may hide their illness [9]. Schizophrenia can occur in adolescence [8], although parents may not acknowledge a child's symptoms, due to stigma. In addition, even when parents do acknowledge symptoms, they might choose to hide them instead of seeking medical care.

As compared with fathers, mothers tend to spend more time with their children. Therefore, negative maternal attitudes toward schizophrenia may lead to lack of treatment for mental illness in their children [10]. However, studies of mothers caring for their children (including adolescents) have not thoroughly examined the association between social distance toward schizophrenia and treatment. In this study, we used the social distance scale to examine the extent of negative attitudes toward schizophrenia among mothers of adolescents. The Social Distance scale Japanese Version is an evidence-based instrument that is translated from a commonly used scale. In addition, we examined hypothetical help-seeking among mothers when a child has a mental illness. We hypothesized that social distance toward schizophrenia 
would mediate the relation with maternal help-seeking at any psychiatric facility or department and that mothers with greater social distance would not seek help at a mental hospital. In this prospective cohort study, we examined the relation between negative attitudes toward schizophrenia and help-seeking among mothers of junior and senior high school students in Japan.

\section{PARTICIPANTS AND METHODS}

\subsection{Participants}

The participants were 1309 Japanese mothers of 696 junior high school students and 613 senior high school students and were extracted from 1,370,000 candidates included in a database administered by a Japanese private company specializing in questionnaire research. Stratified random sampling was used, as previously described [11-13]. The study was approved by the Ethics Committee of the Niigata University School of Medicine.

\subsection{Measurement}

The participants completed a questionnaire that requested information on sociodemographic data. Social distance was evaluated by using the Social Distance Scale-Japanese version (SDS-J) [14]. The items on the scale are answered using a 4-point Likert scale: 3, strongly agree; 2 , tend to agree; 1 , tend to disagree; and 0 , strongly disagree. A higher score indicates greater social distance. A detailed explanation of this questionnaire has been previously published [15].

Mothers were also asked about what help they would seek if they had a child with sleeplessness, social withdrawal, and strange behavior. Specifically, they were asked the type of medical facility at which they would seek a consultation. The details of this questionnaire have been previously published [13].

\subsection{Statistical Analysis}

All analyses were performed using the Statistical Package for Social Sciences (SPSS), version 18.0. Oneway analysis of variance and Student's t-test were used to examine the associations between social distance toward schizophrenia and maternal demographic characteristics and the associations between social distance and help-seeking.

\section{RESULTS}

\subsection{Participant Characteristics}

Most (76.4\%) participants were aged 40 - 49 years (Table 1), and 540 (41.3\%) were full-time housewives. Most respondents (54.5\%) reported a family income of
53,000 - 110,000 US dollars, and 112 (8.5\%) reported participation in welfare activities for people with mental illnesses. The findings were discussed in detail in our previous report [11-13].

\subsection{Relation between Social Distance and Maternal Demographic Characteristics}

The mean score \pm SD on the Social Distance Scale was $12.2 \pm 3.9$ (range, 0 - 24). Maternal demographic characteristics significantly associated with social distance were employment and participation in welfare activities for people with mental illness (Table 1). The mean score for mothers who had not taken part in welfare activities for people with mental illness was higher than that for mothers who had. The mean score for self-employed mothers was the highest among employed mothers.

\subsection{Relation between Social Distance and Help-Seeking}

On the questionnaire that asked about hypothetical help-seeking for a child with sleeplessness, social withdrawal, and strange behavior, there was no significant association between maternal social distance and the likelihood of seeking psychiatric help $(\mathrm{p}=0.060$; Table 2). However, maternal social distance was significantly inversely associated with seeking help at a psychiatric clinic ( $p=0.003)$ and at the child's school $(p=0.003)$. There was no significant association with seeking help at a mental hospital, department of psychosomatic medicine, or department of internal medicine $(p=0.064, p=0.077$, and $\mathrm{p}=0.966$, respectively), or with treatment timing ( $\mathrm{p}$ $=0.909$ ).

\section{DISCUSSION}

Parental attitudes toward schizophrenia are an important factor in early detection and intervention for a child with schizophrenia [11] because negative attitudes toward schizophrenia are associated with delayed treatment [4], which has a negative effect on prognosis $[16,17]$. In addition, because people with schizophrenia typically have little understanding of the disorder, family support is very important for early detection and treatment.

The limited number of previous studies of attitudes toward schizophrenia among parents of adolescents have mostly focused on factors that affect those attitudes $[11,18]$. Demographic characteristics significantly associated with parental attitudes were family income, occupation, presence of a neighbor with schizophrenia, and participation in welfare activities for people with mental illness [11]. Explanation for the discrepancy between the findings of studies of mothers and studies of parents was 
Table 1. Distribution of scores on Social Distance Scale-Japanese version (SDS-J), by maternal demographic characteristics.

\begin{tabular}{|c|c|c|c|}
\hline & & SDS-J & \\
\hline & $\mathbf{n}$ & Mean \pm SD & $\mathbf{p}^{*}$ \\
\hline Age (years) & & & $\mathrm{p}=0.267$ \\
\hline $30-39$ & 178 & $12.14 \pm 3.46$ & \\
\hline $40-49$ & 1000 & $12.26 \pm 3.97$ & \\
\hline $50-59$ & 129 & $11.63 \pm 4.14$ & \\
\hline $60-69$ & 2 & $9.50 \pm 2.12$ & \\
\hline Occupation & & & $\mathrm{p}=0.529$ \\
\hline Agriculture, forestry, and fisheries & 3 & $12.00 \pm 0.00$ & \\
\hline Production labor services & 135 & $12.48 \pm 3.92$ & \\
\hline Transportation and communications & 26 & $13.12 \pm 4.07$ & \\
\hline Sales and marketing & 141 & $12.62 \pm 3.85$ & \\
\hline Service industry & 162 & $12.01 \pm 3.78$ & \\
\hline Professional & 204 & $12.10 \pm 4.14$ & \\
\hline Other & 638 & $12.05 \pm 3.90$ & \\
\hline Employment & & & $\mathrm{p}=0.017$ \\
\hline Full-time & 227 & $12.36 \pm 3.68$ & \\
\hline Part-time & 461 & $12.17 \pm 4.00$ & \\
\hline Self-employed & 62 & $13.03 \pm 4.47$ & \\
\hline Full-time housewife & 540 & $12.10 \pm 3.83$ & \\
\hline Unemployed & 19 & $9.58 \pm 4.62$ & \\
\hline Annual family income, (US dollars) & & & $\mathrm{p}=0.100$ \\
\hline$<11,000$ & 25 & $12.80 \pm 4.22$ & \\
\hline $11,000-32,000$ & 130 & $12.19 \pm 4.04$ & \\
\hline $32,000-53,000$ & 255 & $11.95 \pm 4.20$ & \\
\hline $53,000-110,000$ & 713 & $12.06 \pm 3.76$ & \\
\hline$>110,000$ & 186 & $12.86 \pm 3.97$ & \\
\hline Participation in welfare activities for people with mental illness & & & $\mathrm{p}=0.001$ \\
\hline Yes & 112 & $10.83 \pm 3.87$ & \\
\hline No & 1197 & $12.31 \pm 3.90$ & \\
\hline
\end{tabular}

*Student's t-test; one-way analysis of variance.

not significantly associated to age, occupation, and family income. In the present study, $76.5 \%$ of mothers were part-time workers or full-time housewives; thus, family income depended primarily on fathers. Maternal occupation was not significantly associated with social distance, which differs from the results of Lysaker et al. [5]. Put another way, the present results show that maternal social status was not associated with attitudes toward schizophrenia.

We examined the association of maternal social distance toward schizophrenia with the likelihood of medi- cal consultation, the type of consultation sought, and the timing of treatment for a child with symptoms of mental illness. The results showed that level of maternal social distance was not associated with likelihood of seeking psychiatric help or treatment timing. These findings are new and somewhat contradictory to our study hypothesis and earlier findings. Indeed, a number of studies have shown that a negative attitude toward schizophrenia is associated with a lower likelihood of seeking psychiatric help [4-6].

These differing results may be due to differences in the 
Table 2. Association of SDS-J with help-seeking among mothers.

\begin{tabular}{|c|c|c|c|}
\hline \multirow{2}{*}{ Type of consultation } & \multicolumn{3}{|c|}{ SDS-J score } \\
\hline & $\mathbf{n}$ & Mean \pm SD & $\mathbf{p}$ \\
\hline Any psychiatric consultation & & & $\mathrm{p}=0.060$ \\
\hline Yes & 853 & $12.03 \pm 4.02$ & \\
\hline No & 456 & $12.46 \pm 3.72$ & \\
\hline Mental hospital & & & $\mathrm{p}=0.064$ \\
\hline Yes & 177 & $11.66 \pm 4.04$ & \\
\hline No & 1132 & $12.26 \pm 3.90$ & \\
\hline Dept. of psychosomatic medicine & & & $\mathrm{p}=0.077$ \\
\hline Yes & 713 & $12.00 \pm 3.92$ & \\
\hline No & 596 & $12.39 \pm 3.91$ & \\
\hline Psychiatric clinic & & & $\mathrm{p}=0.003$ \\
\hline Yes & 309 & $11.61 \pm 4.21$ & \\
\hline No & 1000 & $12.36 \pm 3.81$ & \\
\hline Dept. of internal medicine & & & $\mathrm{p}=0.966$ \\
\hline Yes & 77 & $12.19 \pm 3.19$ & \\
\hline No & 1232 & $12.18 \pm 3.96$ & \\
\hline Timing of medical & & & $\mathrm{p}=0.909$ \\
\hline \multicolumn{4}{|l|}{ Help-seeking } \\
\hline Within 1 week & 565 & $12.26 \pm 4.05$ & \\
\hline About 1 month later & 605 & $12.10 \pm 3.75$ & \\
\hline About 6 months later & 96 & $12.29 \pm 3.73$ & \\
\hline More than 1 year later & 21 & $12.24 \pm 5.29$ & \\
\hline Non-medical help sought & 22 & $11.64 \pm 4.46$ & \\
\hline School & & & $\mathrm{p}=0.003$ \\
\hline Yes & 554 & $11.80 \pm 3.81$ & \\
\hline No & 755 & $12.46 \pm 3.98$ & \\
\hline
\end{tabular}

SDS-J, Social Distance Scale-Japanese version.

medical systems of Japan and other countries. In Western countries most people have primary care physicians [19], who would be the first medical professional to be consulted in the event of symptoms of medical illness. Then, if necessary, primary care physicians would refer the patients to specialists in counseling or psychiatry. Most Japanese do not have a regular primary care physician and can freely seek specialist psychiatric care. Treatment and consultation in an outside community are also possible. Therefore, Japanese mothers might feel fewer constraints, and can seek medical help at any time. However, Japanese mothers might be more concerned than their Western peers about public scrutiny, as suggested by the reluctance of mothers with greater social distance to seek help at their child's school (Table 2). In other words, mothers may desire to hide their child's potential mental illness from school authorities.

We also found that a negative attitude toward schizophrenia affected the type of hospital selected, namely, it significantly reduced maternal help-seeking at psychiatric clinics. This result differs from the findings of a study by Platz et al., which showed that a substantial number of contacts with mental health care professionals were made along help-seeking pathways. The label of schizophrenia is related to stigma [20,21]. In Japan, the disease name was changed from seishin bunretsu byou to tougou shicchou shou in 2002, after which the proportion of patients who were informed of their diagnosis increased from $36.7 \%$ to $69.7 \%$ in 3 years $[22,23]$. Therefore, the disease name likely affects the public image of 
the disease. Mothers that avoid psychiatric clinics may have an unfavorable image of such clinics. However, the number of psychiatric clinics is increasing in Japan. Future research should focus on understanding why these negative attitudes cause individuals to avoid only psychiatric clinics. In addition, if the case is to be made that negative attitudes have a substantial effect on illness evaluation, researchers should examine whether such attitudes are linked to other disease components, such as depression.

We would like to highlight three points from our results. First, when symptoms of mental illness occur in children, mothers should quickly seek expert evaluation and treatment because delayed treatment is linked to worse prognosis [1]. Second, schools should improve mental-health support systems, the most important aspect of which is specialist treatment by a psychiatrist. Most children commute to school, so adequate mental-health support systems at schools are important. The school should be a supportive environment where mothers can comfortably discuss their child's mental health problems. Third, methods to address stigma are essential. These three points may assist in early detection and intervention for schizophrenia in adolescents.

\section{ACKNOWLEDGEMENTS}

The authors thank the study participants. This work was supported by a 2010 Grant-in-Aid for Scientific Research (C) from the Japan Society for the Promotion of Science (22592581), entitled "Investigations of the Consciousness of Parents of Junior and Senior High School Students Concerning Schizophrenia and the Development of Educational Enlightenment Media”. None of the authors has any conflicts of interest associated with this study.

\section{REFERENCES}

[1] Chong, S.A., Lee, C., Bird, L. and Verma, S. (2004) A risk reduction approach for schizophrenia: The early psychosis intervention programme. ANNALS Academy of Medicine Singapore, 33, 630-635.

[2] Van, O.J. and Delespaul, P. (2005) Toward a world consensus on prevention of schizophrenia. Dialogues in Clinical Neuroscience, 7, 53-67.

[3] Yung, A.R., Killackey, E., Hetrick, S.E., Parker, A.G., Schultze-Lutter, F., Klosterkoetter, J., et al. (2007) The prevention of schizophrenia. International Review of Psychiatry, 19, 633-646. doi:10.1080/09540260701797803

[4] Tanaka, G., Ogawa, T., Inadomi, H., Kikuchi, Y. and Ohta, Y. (2003) Effects of an education program on public attitudes towards mental illness. Psychiatry and Clinical Neurosciences, 57, 595-602. doi:10.1046/j.1440-1819.2003.01173.x

[5] Lysaker, P.H., Davis, L.W., Warman, D.M., Strasburger, A. and Beattie, N. (2007) Stigma social function and symp- toms in schizophrenia and schizoaffective disorder: Associations across 6 months. Psychiatry Research, 149, 8995.

[6] Esterberg, M.L., Compton, M.T., McGee, R., Shim, R. and Hochman, K. (2008) Knowledge about schizophrenia and social distance toward individuals with schizophrenia: a survey among predominantly low-income, urban, African American community members. Journal of Psychiatric Practice, 14, 86-93.

doi:10.1097/01.pra.0000314315.94791.80

[7] Penn, D.L., Kohlmaier, J.R. and Corrigan, P.W. (2000) Interpersonal factors contributing to the stigma of schizophrenia: Social skills, perceived attractiveness, and symptoms. Schizophrenia Research, 45, 37-45. doi:10.1016/S0920-9964(99)00213-3

[8] Berge, M. and Ranney, M. (2005) Self-esteem and stigma among persons with schizophrenia: Implications for mental health. Care Management Journals, 6, 139-144. doi:10.1891/cmaj.6.3.139

[9] Corrigan, P.W., Green, A., Lundin, R., Kubiak, M.A. and Penn, D.L. (2001) Familiarity with and social distance from people who have serious mental illness. Psychiatric Services, 52, 953-958. doi:10.1176/appi.ps.52.7.953

[10] Wright, A., Jorm, A.F. and Mackinnon, A.J. (2011) Labeling of mental disorders and stigma in young people Social Science \& Medicine, 7, 498-506. doi:10.1016/j.socscimed.2011.06.015

[11] Yoshii, H., Watanabe, Y., Kitamura, H., Nan, Z. and Akazawa, K. (2011) Stigma toward schizophrenia among parents of junior and senior high school students in Japan. BMC Research Notes, 4, 558. doi:10.1186/1756-0500-4-558

[12] Yoshii, H., Watanabe, Y., Kitamura, H., Chen, J. and Akazawa, K. (2011) Effect of an education program on improving knowledge of schizophrenia among parents of junior and senior high school students in Japan. BMC Public Health, 11, 323. doi:10.1186/1471-2458-11-323

[13] Yoshii, H., Watanabe, Y., Kitamura, H., Nan, Z. and Akazawa, K. (2012) Effect of an education program on improving help-seeking among parents of junior and senior high school students in japan. Global Journal of Health Science, 4, 33-41.

[14] King, M., Dinos, S., Shaw, J., Watson, R., Stevens, S., Passetti, F., et al. (2007) The stigma scale: Development of astandardised measure of the stigma of mental illness. The British Journal of Psychiatry, 190, 248-254. doi:10.1192/bjp.bp.106.024638

[15] Yoshii, H., Watanabe, Y., Kitamura, H., Ling, Y. and Akazawa, K. (2012) Social distance toward schizophrenia among parents of adolescents. Health, 4, 386-391. doi:10.4236/health.2012.47061

[16] Loebel, A.D., Lieberman, J.A., Alvir, J.M., Mayerhoff, D.I., Geisler, S.H. and Szymanski, S.R. (1992) Duration of psychosis and outcome in first-episode schizophrenia. American Journal of Psychiatry, 149, 1183-1188.

[17] Helgason, L. (1990) Twenty years' follow-up of first psychiatric presentation for schizophrenia: What could have been prevented? Acta Psychiatrica Scandinavica, 81, 231- 
235. doi:10.1111/j.1600-0447.1990.tb06486.x

[18] Jorm, A.F. and Wright, A. (2008) Influences on young people's stigmatising attitudes towards peers with mental disorders: National survey of young Australians and their parents. The British Journal of Psychiatry, 192, 144-149. doi:10.1192/bjp.bp.107.039404

[19] Riedel-Heller, S.G., Matschinger, H. and Angermeyer, M.C. (2005) Mental disorders who and what might help? Help-seeking and treatment preferences of the lay public. Social Psychiatry and Psychiatric Epidemiology, 40, 167174. doi:10.1007/s00127-005-0863-8

[20] Alison, J.G. (2002) Stigma in psychiatry. Journal of the Royal Society of Medicine, 95, 72-76. doi:10.1258/jrsm.95.2.72
[21] Blignault, I., Woodland, L., Ponzio, V., Ristevski, D. and Kirov, S. (2009) Using a multifaceted community intervention to reduce stigma about mental illness in an Australian Macedonian community. Health Promotion Journal of Australia, 20, 227-233.

[22] Umehara, H., Fangerau, H., Gaebel, W., Kim, Y., Schott, H. and Zielasek, J. (2011) From "schizophrenia” to "disturbance of the integrity of the self”: Causes and consequences of renaming schizophrenia in Japan in 2002 Der Nervenarzt, 82, 1160-1168. doi:10.1007/s00115-010-3208-0

[23] Sato, M. (2006) Renaming schizophrenia: A Japanese perspective. World Psychiatry, 5, 53-55. 